\title{
Thyroid transcription factor 1 and p63 expression is associated with survival outcome in patients with non-small cell lung cancer treated with erlotinib
}

\author{
MARTIN SVATON $^{1}$, ONDREJ FIALA ${ }^{2,3}$, GABRIELA KRAKOROVA $^{1}$, JIRI BLAZEK $^{1}$, \\ KAROLINA HURDALKOVA ${ }^{4}$, MAGDA BARINOVA ${ }^{4}$, PETR MUKENSNABL ${ }^{5}$ and MILOS PESEK $^{1}$ \\ Departments of ${ }^{1}$ Pneumology and Phthisiology, and ${ }^{2}$ Oncology and Radiotherapy; ${ }^{3}$ Biomedical Center, \\ Faculty of Medicine in Pilsen, Charles University, 30599 Pilsen; ${ }^{4}$ Institute of Biostatistics and Analyses Ltd., \\ 62500 Brno; ${ }^{5}$ Department of Pathology, Faculty of Medicine in Pilsen, Charles University, 30599 Pilsen, Czech Republic
}

Received November 12, 2019; Accepted April 16, 2020

DOI: 10.3892/ol.2020.11663

\begin{abstract}
While erlotinib is primarily administered to patients with non-small cell lung cancer with sensitizing epidermal growth factor receptor (EGFR) mutations, it is also prescribed to patients with wild type (wt) EGFR in higher lines of treatment. However, there is no predictive marker for erlotinib efficacy in patients with EGFR wt. Certain immunohistochemical (IHC) parameters, including thyroid transcription factor 1 (TTF1) and p63, have been reported to indicate predictive power in patients with EGFR wt. The present study focused on retrospective data from the University Hospital in Pilsen using the TULUNG register. TTF1 and p63 expression data were extracted from the hospital information system and merged with registry data to calculate progression-free survival (PFS) and overall survival (OS) rates. A cohort of 345 patients with adenocarcinoma (ADC) or squamous cell carcinoma (SCC) exhibited similar erlotinib efficacies when TTF1 and p63 were ignored. However, significant differences were reported in PFS and OS rates of a subgroup of 126 patients where TTF1 and p63 parameters were known. In a univariate analysis, group A (ADC TTF1+/p63-) achieved PFS of 2.6 months, group B (SSC TTF1-/p63+) 1.9 months and group C (did not fit into groups A or B, i.e., ADC TTF1-/p63+ or SCC TTF1+/p63-) 1.4 months $(\mathrm{P}=0.006)$. Median OS was 14.2, 19.1 and 5.3 months for $\mathrm{A}$, $\mathrm{B}$ and $\mathrm{C}$, respectively $(\mathrm{P}=0.002)$. Furthermore, a multivariate analysis demonstrated IHC markers to be the only significant parameters for PFS and OS. Group C had a negative prognostic factor for PFS [hazard ratio (HR), 1.812; $\mathrm{P}=0.02$ ] and $\mathrm{OS}(\mathrm{HR}=2.367 ; \mathrm{P}=0.01)$. In conclusion, patients with EGFR wt
\end{abstract}

Correspondence to: Dr Martin Svaton, Department of Pneumology and Phthisiology, Faculty of Medicine in Pilsen, Charles University, E. Benese 13, 30599 Pilsen, Czech Republic

E-mail: svatonm@fnplzen.cz

Key words: non-small cell lung cancer, erlotinib, thyroid transcription factor one, p63, prediction, prognostic and lung carcinomas without TTF1 and $\mathrm{p} 63$ expression typical for ADC (TTF1+/p633-) or SCC (TTF1-/p63+) do not appear to be suitable candidates for erlotinib treatment.

\section{Introduction}

Lung cancer is one of the leading causes of cancer-associated morbidity and mortality in developed countries $(1,2)$. Non-small cell lung cancer (NSCLC), comprising mainly adenocarcinomas (ADCs) and squamous cell carcinomas (SCCs), is the most common histological type, accounting for $>80 \%$ of all lung carcinomas (3).

Erlotinib is a tyrosine kinase inhibitor that inhibits epidermal growth factor receptor (EGFR) (4). Sensitizing mutations in the EGFR gene are a predictive factor for erlotinib use in first-line treatment (5). However, it has been hypothesized that erlotinib may be effective in further treatment lines in patients with wild type (wt) EGFR who lack proven mutations based on data from lung SCC where EGFR sensitizing mutations are rare (6). Due to the higher effectiveness of chemotherapy, erlotinib is primarily administered in third-line treatment for EGRF wt patients with lung carcinomas (7). Third-line erlotinib therapy has been demonstrated to be effective in a small percentage of patients with EGFR-wt NSCLC (6). Therefore, further research may be beneficial in identifying a predictive marker for the successful use of erlotinib (6). Immunohistochemical (IHC) parameters, such as thyroid transcription factor 1 (TTF1) or p63, may be candidate predictors (8).

TTF1 is a nuclear protein transcription factor that is utilized as a marker for lung adenocarcinoma diagnosis (9). The prognostic role of TTF1 expression in patients with NSCLC has been previously assessed in several studies with conflicting results (10-12). Previous studies initially hypothesized TTF1 may serve a prognostic role in early NSCLC and later reported a possible role in advanced NSCLC, as confirmed by subsequent meta-analyses $(13,14)$.

p63 is a gene located on chromosome $3 q$ and is a member of the p53 family (15). p63 serves a major role in the cell cycle and squamous cell differentiation (9). Additionally, p63 has 
been described as a possible prognostic marker for NSCLC, despite conflicting results $(16,17)$. For example, Ma et al (16) demonstrated that high p63 expression was associated with better prognosis, while Pelosi et al (17) did not identify any prognostic influence of p63 in patients with NSCLC, despite p63 immunoreactivity being connected with tumor grading.

The current retrospective study evaluated the association between TTF1 and p63 expression and outcome for patients with EGRF wt NSCLC treated with erlotinib in second- or third-line therapies.

\section{Materials and methods}

Data source. TULUNG (tulung.registry.cz) is a non-interventional post-registration multi-center database that lists the epidemiological and clinical data of patients with advanced NSCLC treated with targeted or novel therapies in the Czech Republic. The registry contains anonymized individual patient data, including demographic parameters, initial staging and disease characteristics, baseline patient information at the beginning of targeted therapy and data on survival and adverse events. TTF1 and p63 expression data were extracted from the hospital information system of the University Hospital in Pilsen and merged with registry data. The TULUNG registry project, including further use of its data, was approved by the Local Ethics Committee of the University Hospital in Pilsen. All patients gave written informed consent to participate.

Patients and treatment. A total of 345 adult patients ( $>18$ years old) from the University Hospital in Pilsen with histologically confirmed locally advanced (IIIB) or metastatic (IV) stage EGRF wt NSCLC treated with erlotinib between January 2008 and December 2018 entered in the TULUNG registry (the database was screened for patients admitted at these dates). Erlotinib was administered orally at a standard approved dose (150 mg daily until disease progression or discontinuation due to side effects) as second- or third-line treatment as per routine clinical practice. Dose interruption (for maximum 1 month) or reduction (to 100 or $50 \mathrm{mg}$ daily) was permitted in the event of treatment-related toxicity. The Eastern Cooperative Oncology Group performance status (ECOG PS) was determined according to established criteria (https://ecog-acrin. org/resources/ecog-performance-status). According to national guidelines, EGFR mutations are not commonly investigated in patients with SCC (18). A total of 9 patients had ADC in the unknown subcategory (due to lack of biopsy material for EGFR testing).

Clinical monitoring. Treatment was prospectively monitored and assessed at regular time intervals as per routine clinical practice. Clinical follow-ups, including physical examinations, plain chest X-rays and routine laboratory tests (hematology and basic biochemical tests) were performed every 3-4 weeks, until January 2019. Computed tomography or positron emission tomography was performed every 2-3 months.

Assessment of TTF1 and p63 expression. NSCLC diagnoses were established from lung tissue samples collected during bronchoscopy or computed tomography/ultrasound-guided biopsy at the University Hospital in Pilsen. Tissue were fixed for $24 \mathrm{~h}$ at room temperature using $10 \%$ neutral buffered formalin. All samples were cut into $4-\mu \mathrm{m}$-thick sections and embedded in paraffin. IHC staining, including antigen retrieval and blocking, was performed using a Ventana Benchmark XT automated stainer (Ventana Medical Systems, Inc.), according to the manufacturer's protocol. Slides were incubated with mouse monoclonal anti-TTF1 clone SPT24 primary antibody (1:400; cat. no. NCL-L-TTF-1; Novocastra Laboratories Ltd.) at $37^{\circ} \mathrm{C}$ for $32 \mathrm{~min}$ and mouse monoclonal anti-p63 clone $4 \mathrm{~A} 4$ primary antibody (ready to use; cat. no. 790-4509; Ventana Medical Systems, Inc.) at $37^{\circ} \mathrm{C}$ for $24 \mathrm{~min}$, followed by secondary antibody incubation using the ultraView Universal DAB detection kit (Ventana Medical Systems, Inc.) for $8 \mathrm{~min}$ at room temperature. Subsequently, slides were stained with hematoxylin for $8 \mathrm{~min}$ at room temperature, and observed under an Olympus BX 540 light microscope (Olympus Corporation; magnification, $\mathrm{x} 200)$. IHC staining was scored using a two-tiered scoring system: positive or negative. A positive score was based on moderate to strong nuclear staining obtained during routine IHC testing for NSCLC diagnosis by a trained pathologist. Staining was compared to a positive external control, such as thyroid gland tissue for TTF1 and skin for p63. The routine investigation was certified according to the Czech standards, European standards and International Organization for Standardization (biopticka.cz/cz/laborator/doc/Akreditace\%20-\%20Priloha.pdf) by an accredited laboratory (Biopticka laborator s.r.o.; http://www.biopticka. cz/cz/laborator/doc/Akreditace.pdf). TTF1 and p63 positive and negative staining is demonstrated in Fig. 1.

Statistical analysis. The entire TULUNG cohort was analyzed to assess treatment results in all patients treated with erlotinib. Analysis was based on histology irrespective of TTF1/p63 expression. Additionally, a subgroup of patients with known TTF1/p63 expression was assessed (from the aforementioned hospital database). Standard descriptive statistics were used to characterize the sample dataset. Statistical analyses were performed using SPSS v25.0 (IBM Corp.) and R software version 3.5.1 (https://www.R-project.org/). Description of continuous characteristics of patients was presented as the mean $\pm \mathrm{SD}$, or as the median with minimum and maximum. If appropriate, continuous variables were categorized according to common cut-off points. Summary of categorical parameters was performed using absolute and relative frequencies. Relative frequencies were calculated as percentages from the number of patients in the relevant subgroup.

Progression free survival (PFS) and overall survival (OS) were estimated using the Kaplan-Meier method and all point estimates were complemented with $95 \%$ confidence intervals (CIs). PFS was determined from the date of erlotinib treatment initiation and the date of the first documented progression (measured by Response Evaluation Criteria in Solid Tumors; version 1.1) (19) or death due to any cause. OS was determined from the date of erlotinib treatment initiation and the date of death due to any cause. Patients who had not progressed or died were censored at the date of the last follow-up. Statistical significance of the differences in Kaplan-Meier estimates were assessed using the log-rank test. Furthermore, a multivariate Cox proportional hazards model was utilized to evaluate the effect of all potential prognostic clinical/IHC factors on 
Table I. Baseline patient characteristics of 126 patients with $\mathrm{ADC}$ or SCC.

\begin{tabular}{|c|c|c|}
\hline Characteristics & No. & Percentage \\
\hline \multicolumn{3}{|l|}{ Age, years } \\
\hline$<65$ & 78 & 61.9 \\
\hline$\geq 65$ & 48 & 38.1 \\
\hline Median (min-max) & $62(28-78)$ & \\
\hline \multicolumn{3}{|l|}{ Sex } \\
\hline Male & 77 & 61.1 \\
\hline Female & 49 & 38.9 \\
\hline \multicolumn{3}{|c|}{ EGOG PS at treatment initiation } \\
\hline 0 & 4 & 3.2 \\
\hline 1 & 91 & 72.2 \\
\hline$\geq 2$ & 31 & 24.6 \\
\hline \multicolumn{3}{|c|}{ Stage at treatment initiation } \\
\hline IIIB & 38 & 30.2 \\
\hline IV & 88 & 69.8 \\
\hline \multicolumn{3}{|l|}{ EGFR mutation } \\
\hline Negative & 88 & 69.8 \\
\hline Unknown $^{\mathrm{a}}$ & 38 & 30.2 \\
\hline \multicolumn{3}{|l|}{ Smoking } \\
\hline Smokers & 74 & 58.7 \\
\hline Ex-smokers & 31 & 24.6 \\
\hline Non-smokers & 21 & 16.7 \\
\hline \multicolumn{3}{|l|}{ Line of therapy } \\
\hline Second-line & 63 & 50.0 \\
\hline Third line & 63 & 50.0 \\
\hline \multicolumn{3}{|l|}{ Histology } \\
\hline $\mathrm{ADC}$ & 68 & 54.0 \\
\hline SCC & 58 & 46.0 \\
\hline
\end{tabular}

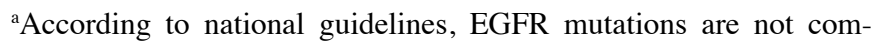
monly investigated in patients with SCC. A total of 9 patients had $\mathrm{ADC}$ in the unknown subcategory. ADC, adenocarcinoma; SCC, squamous cell carcinoma; ECOG PS, Eastern Co-operative Oncology Group performance status; EGFR, epidermal growth factor receptor.

survival measures. $\mathrm{P}<0.05$ was considered to indicate a statistically significant difference.

To assess the effect of the IHC factors, patients with NSCLC were split into three groups: A, patients with ADC who were TTF1 positive (TTF1+) and p63 negative (p63-); B, patients with SCC who were TTF1-/p63+; and C, patients who did not fall into any of the previous groups, including patients with ADC TTF1-/p63+ or SCC TTF1+/p63-.

\section{Results}

Patient characteristics. TULUNG contained data on 345 patients treated with erlotinib when the current study commenced. The baseline characteristics of a subgroup of 126 patients with known TTF1/p63 expression are summarized in Table I, while the remaining 219 patients were
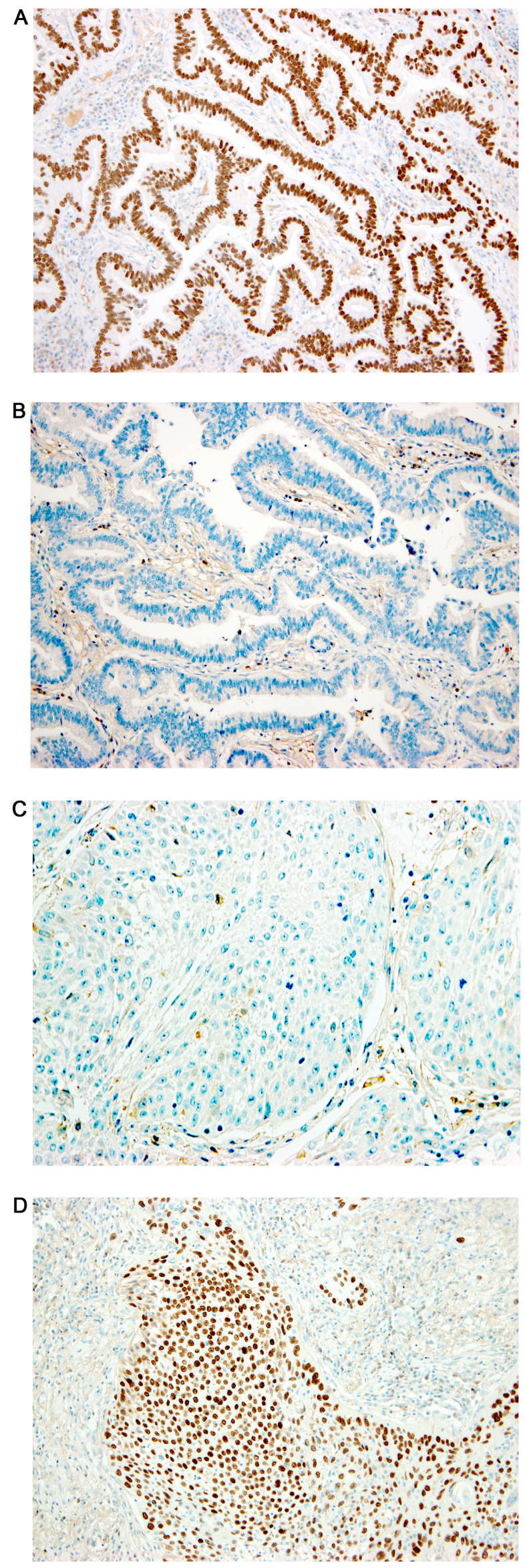

Figure 1. Immunohistochemical expression in the nuclei of examined tumors. Lung adenocarcinoma with (A) TTF1 positivity and (B) p63 negativity. Lung squamous cell carcinoma with (C) TTF1 negativity and (D) p63 positivity. Magnification, $\mathrm{x} 200$. TTF1, thyroid transcription factor 1 . 
Table II. Demographic characteristic of patients in group A $(n=40), B(n=49)$ and C $(n=37)$.

\begin{tabular}{lccc}
\hline Characteristics & Group A & Group B & Group C \\
\hline $\begin{array}{l}\text { Sex, } \mathrm{n}(\%) \\
\text { Male }\end{array}$ & $22(55.0)$ & $36(73.5)$ & $19(51.4)$ \\
Female & $18(45.0)$ & $13(26.5)$ & $18(48.6)$ \\
Age, $\mathrm{n}(\%)$ & & & $23(76.9)$ \\
$<65$ years & $29(72.5)$ & $26(53.1)$ & $11(29.7)$ \\
$\geq 65$ years & $11(27.5)$ & $65.0(49.0-78.0)$ & $60.0(28.0-72.0)$ \\
Median (min-max) & $60.5(28.0-76.0)$ & & \\
\hline
\end{tabular}

Table III. PFS and OS for 345 patients with ADC or SCC verified either cytologically or histologically.

\begin{tabular}{|c|c|c|c|}
\hline Verification & $\mathrm{ADC}$ & SCC & P-value \\
\hline \multicolumn{4}{|l|}{ Verified cytologically } \\
\hline No. of patients & 112 & 101 & \\
\hline Median PFS, months (95\% CI) & $1.9(1.7 ; 22)$ & $1.9(1.8 ; 2.1)$ & 0.70 \\
\hline Median OS, months $(95 \%$ CI) & $10.6(7.1 ; 14.0)$ & $8.2(5.8 ; 10.5)$ & 0.78 \\
\hline \multicolumn{4}{|l|}{ Verified histologically } \\
\hline No. of patients & 70 & 62 & \\
\hline Median PFS, months $(95 \% \mathrm{CI})$ & $1.9(1.5 ; 2.3)$ & $1.9(1.2,2.7)$ & 0.15 \\
\hline Median OS, months $(95 \% \mathrm{CI})$ & $13.2(7.7 ; 18.9)$ & $19.5(9.1 ; 29.6)$ & 0.87 \\
\hline
\end{tabular}

PFS, progression-free survival; OS, overall survival; ADC, adenocarcinoma; SCC, squamous cell carcinoma; CI, confidence interval.

excluded due to unknown TTF1/p63 expression status. These patients were further divided into groups $\mathrm{A}, \mathrm{B}$ and $\mathrm{C}$ as aforementioned, which included 40, 49 and 37 patients, respectively. Of these 126 patients, 2 had to reduce the dose (to $100 \mathrm{mg}$ daily) and 3 had to discontinue treatment prematurely due to side effects (e.g. rash) of erlotinib. The demographic characteristics of patients in subgroups A, $\mathrm{B}$ and $\mathrm{C}$ are summarized in Table II.

Survival of patients in the entire TULUNG group irrespective of TTF1/p63 expression. No significant differences in PFS and OS were identified between patients with SCC and ADC, whether their condition was determined cytologically or histologically (Table III). There were no statistically significant differences between PFS and OS for cytological vs. histological determination of samples in a total group of patients (ADC, OS P=0.098 and PFS $\mathrm{P}=0.808$; SCC, OS P=0.166 and $\mathrm{PFS} P=0.269$; data not shown).

Survival of patients with known TTF1/p63 expression. The current study revealed significant differences in PFS $(\mathrm{P}=0.006)$ and $\mathrm{OS}(\mathrm{P}=0.002)$ between groups $\mathrm{A}, \mathrm{B}$ and $\mathrm{C}$. Median PFS was $2.6(95 \% \mathrm{CI}, 2.0 ; 3.1), 1.9(95 \% \mathrm{CI}, 1.6 ; 2.2)$ and 1.4 $(95 \%$ CI, 0.5; 2.2) months in groups A, B and C, respectively. Median OS was 14.2 (95\% CI, 9.6; 18.9), 19.1 (95\% CI, 10.6; 27.6) and 5.3 (95\% CI, 3.2; 7.5) months in groups A, B and C, respectively. Survival curves for PFS and OS are presented in Figs. 2 and 3, respectively.
Multivariate analysis. The multivariate Cox proportional hazards model (Table IV) demonstrated significant associations between PFS and IHC parameters in groups $\mathrm{A}(\mathrm{P}=0.03)$ and $\mathrm{C}(\mathrm{P}=0.02)$. Similarly, a significant association was identified between OS and IHC parameters in groups $\mathrm{A}(\mathrm{P}=0.003)$ and $\mathrm{C}(\mathrm{P}=0.01)$. The only other significant association was between ECOG PS and OS ( $\mathrm{P}=0.03$; Table IV).

\section{Discussion}

The results of the current study suggested that TTF1 and p63 IHC markers may be useful predictors of erlotinib efficacy in patients with EGFR wt lung ADC/SCC. While the present study focused on IHC markers, previous studies have investigated the role of clinical parameters, such as gender, age and ECOG PS (20-22). The results of these studies have been inconsistent and no clinical parameter is currently routinely used as a predictive marker for erlotinib efficacy in patients with EGRF wt. Furthermore, certain parameters, including sex, smoking and histology may be associated with EGFR mutational status (23). In the current study, the majority of patients with unknown EGFR status had SCC (in which EGFR mutations are rare) and no effect of histology was reported. Previous studies have reported similar results $(7,22,24)$. None of the clinical parameters were reported to be associated with outcome in the present cohort, except ECOG PS and OS. Therefore, the current study hypothesized that these clinical parameters alone should not be considered as 
Table IV. Multivariate Cox analysis of 126 patients with ADC or SCC.

\begin{tabular}{lcccr}
\hline & \multicolumn{2}{c}{ PFS } & & OS \\
\cline { 2 - 3 } Parameters & HR $(95 \%$ CI $)$ & P-value & HR $(95 \%$ CI $)$ & P-value \\
\hline Age & $0.982(0.961 ; 1.003)$ & 0.10 & $0.982(0.953 ; 1.012)$ & 0.24 \\
Sex & $0.934(0.636 ; 1.370)$ & 0.73 & $1.532(0.916 ; 2.563)$ & 0.10 \\
Smoking & $1.046(0.629 ; 1.737)$ & 0.86 & $1.037(0.517 ; 2.080)$ & 0.92 \\
ECOG PS & $1.411(0.956 ; 2.080)$ & 0.08 & $1.889(1.083 ; 3.296)$ & 0.03 \\
Stage & $1.192(0.791 ; 1.797)$ & 0.40 & $1.491(0.815 ; 2.728)$ & 0.20 \\
EGFR status & $0.849(0.564 ; 1.278)$ & 0.43 & $0.768(0.417 ; 1.414)$ & 0.40 \\
IHC parameter & & & & 0.003 \\
Group A & 1 (reference category) & 0.03 & & 0.54 \\
Group B & $0.993(0.629 ; 1.567)$ & 0.98 & $0.813(0.417 ; 1.584)$ & 0.01 \\
Group C & $1.812(1.109 ; 2.959)$ & 0.02 & $2.367(1.256 ; 4.462)$ & \\
\hline
\end{tabular}

Age, $<65$ years vs. $\geq 65$ years; Smoking, ex-smoker vs. non-smoker; ECOG PS, 0/1 vs. $\geq 2$; stage; IIIB vs. IV; EGFR status; EGFR negative vs. EGFR unknown. ADC, adenocarcinoma; SCC, squamous cell carcinoma; PFS, progression-free survival; OS, overall survival; ECOG PS, Eastern Cooperative Oncology Group performance status; EGFR, epidermal growth factor receptor; IHC, immunohistochemical; HR, hazard ratio; $\mathrm{CI}$ confidence interval.

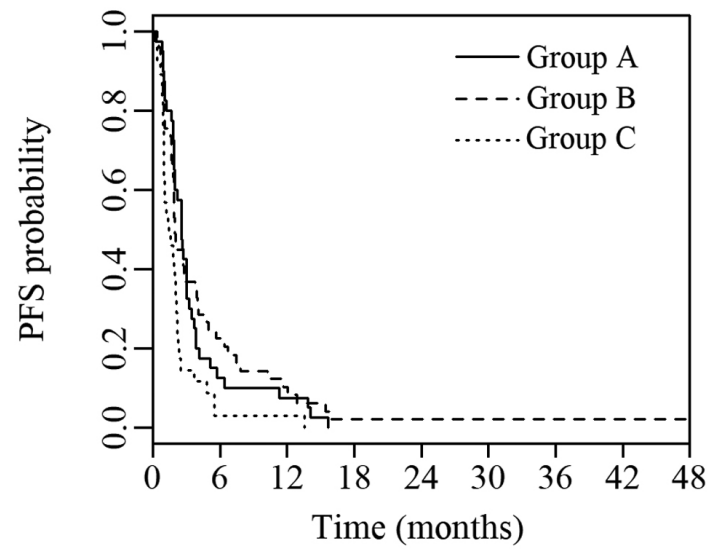

Figure 2. PFS of groups A, B and C with known IHC parameters. Group A (ADC; TTF1+/p63-) vs. B (SCC; TTF1-/p63+) vs. C (ADC or SCC with other IHC characteristics). PFS, progression-free survival; IHC, immunohistochemical; ADC, adenocarcinoma; TTF1, thyroid transcription factor 1; SCC, squamous cell carcinoma.

suitable predictive indicators of erlotinib efficacy in patients with EGFR wt.

Primary investigation into TTF1 and p63 IHC parameters during the current study aimed to determine their possible prognostic use. TTF1 was first described as a marker for distinguishing SCC from ADC $(25,26)$. Additionally, subsequent studies have reported its prognostic significance in other types of NSCLC (27-29). While association between TTF1 and prognosis was initially uncertain in advanced ADC, subsequent meta-analysis has verified its role (14). However, the present study did not take into account the possible effect of EGFR mutations that are more common in TTF1+ ADC (30).

The prognostic role of TTF1 in patients with EGFR wt was demonstrated by Zhu et al (28) in patients who had undergone ADC and SCC tumor resections and exhibited mixed histology. However, there are inconsistent data on the

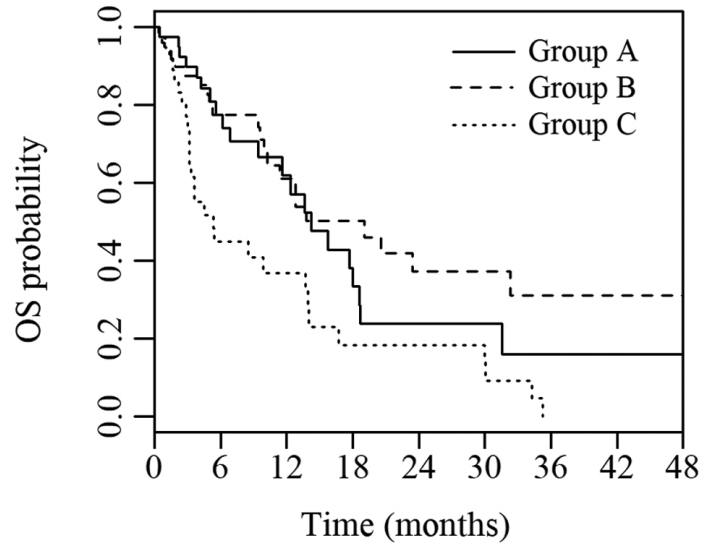

Figure 3. OS of groups A, B and $\mathrm{C}$ with known IHC parameters. Group A (ADC TTF1+/p63-) vs. B (SCC TTF1-/p63+) vs. C (ADC or SCC with other IHC characteristics). OS, overall survival. IHC, immunohistochemical; ADC, adenocarcinoma; TTF1, thyroid transcription factor 1; SCC, squamous cell carcinoma.

effect of p63 on patient prognosis. Ma et al (16) demonstrated improved OS in patients with higher p63 expression in early stage NSCLC. However, Pelosi et al (17) did not observe any prognostic significance of p63 in a patient group with a mix of stages and histological types of NSCLC. The multivariate analysis of patients with advanced NSCLC in the current study demonstrated similar prognoses to patients with ADC TTF1+/p63- and SCC p63+/TTF1- and improved outcome of these two groups compared with tumors that did not exhibit IHC expression. Therefore, the present study hypothesized that IHC expression, disease stage, tumor histology and EGFR status should comprehensively be taken into account. Otherwise, biased results may be obtained as TTF1 expression appeared to be a prognostic factor only in ADC and p63 expression in SCC. Furthermore, different levels of significance of IHC expression cannot be excluded between patients 
who have advanced tumors, have undergone tumor resections or have ADCs with or without EGFR mutations.

The current study demonstrated that patients who exhibited TTF1/p63 expression as expected for the given EGFR wt carcinoma subtype, responded significantly better to erlotinib treatment compared with patients with an atypical IHC profile. While the mechanism of action has not been fully elucidated, it may be associated with TTF1/p63 and EGFR, whose pathological activity is associated with lung cancer (31-34). TTF1 is known to directly exert its effects on EGFR, likely by mediating Leucine-rich immunoglobulin repeats-1 and $\beta$-catenin $(31,32)$. An association between p63 and EGFR has been demonstrated in breast cancer $(33,34)$. Furthermore, Nakahara et al (8) revealed longer time-to-treatment failure and OS in Asian patients with NSCLC EGRF wt who were treated with erlotinib. The current study contributed to the discussion on the predictive power of TTF1/p63 on higher line erlotinib treatment efficacy by providing novel data in two ways. Firstly, the TTF1-related results by Nahakara et al (8) were corroborated in a Caucasian population. Secondly, the present study reported data on the association between p63 expression and the outcome of erlotinib treatment.

Overall, it is necessary to use TTF1 and p63 IHC markers concurrently as this allows differentiation of the prognostic groups described in the present study. Additionally, absence of IHC markers may lead to poor tumor classification (35). However, the current study did not observe statistically significant differences between cytological and histological samples.

The primary limitations of the current study are the retrospective design and relatively small set of patients with known TTF1/p63 expressions from a single institution. Therefore, it would be useful to verify the current thesis in a larger multicenter prospective study.

In conclusion, patients with EGRF wt lung carcinomas that do not exhibit TTF1 and p63 expression for ADC (TTF1+/p63-) or SCC (p63+/TTF1) were reported to have significantly lower PFS and OS, as well as poorer disease prognosis, and do not appear to be suitable candidates for erlotinib treatment.

\section{Acknowledgements}

Not applicable.

\section{Funding}

The current study was supported by Agentura pro zdravotnicky vyzkum (grant no. 17-30748A) and by the National Sustainability Program I (grant no. LO1503) provided by the Ministry of Education, Youth and Sports of the Czech Republic and by the Charles University Research Fund (Progres Q39).

\section{Availability of data and materials}

The data sets used and/or analyzed during the present study are available from the corresponding author on reasonable request.

\section{Authors' contributions}

MS, OF and PM wrote the manuscript. MS, GK, JB, OF, PM and MP analyzed and interpreted the patient general data. $\mathrm{KH}$ and $\mathrm{MB}$ were responsible for the analysis of the observation indicators. All authors read and approved the final manuscript.

\section{Ethics approval and consent to participate}

The processing of data in the TULUNG registry has been approved by the Local Ethics Committee. Signed informed consent from the patients was obtained in the TULUNG registry.

\section{Patient consent for publication}

Not applicable.

\section{Competing interests}

The authors declare that they have no competing interests.

\section{References}

1. Jemal A, Bray F, Center MM, Ferlay J, Ward E and Forman D: Global cancer statistics. CA Cancer J Clin 61: 69-90, 2011.

2. Ferlay J, Parkin DM and Steliarova-Foucher E: Estimates of cancer incidence and mortality in Europe in 2008. Eur J Cancer 46: 765-781, 2010.

3. Brambilla E, Travis WD, Colby TV, Corrin B and Shimosato Y: The new World Health Organization classification of lung tumours. Eur Respir J 18: 1059-1068, 2001.

4. Steins M, Thomas M and Geißler M: Erlotinib. Recent Results Cancer Res 211: 1-17, 2018.

5. Rosell R, Carcereny E, Gervais R, Vergnenegre A, Massuti B, Felip E, Palmero R, Garcia-Gomez R, Pallares C, Sanchez JM, et al; Spanish Lung Cancer Group in collaboration with Groupe Français de Pneumo-Cancérologie and Associazione Italiana Oncologia Toracica: Erlotinib versus standard chemotherapy as first-line treatment for European patients with advanced EGFR mutation-positive non-small-cell lung cancer (EURTAC): A multicentre, open-label, randomised phase 3 trial. Lancet Oncol 13: 239-246, 2012.

6. Tagliamento M, Genova C, Rijavec E, Rossi G, Biello F, Dal Bello MG, Alama A, Coco S, Boccardo S and Grossi F: Afatinib and Erlotinib in the treatment of squamous-cell lung cancer. Expert Opin Pharmacother 19: 2055-2062, 2018.

7. Garassino MC, Kawaguchi T, Gregorc V, Rulli E, Ando M, Marsoni S, Isa SI, Novello S, Farina G, Barni S, et al: Chemotherapy versus erlotinib as second-line treatment in patients with advanced non-small cell lung cancer and wild-type epidermal growth factor receptor: An individual patient data (IPD) analysis. ESMO Open 3: e000327, 2018.

8. Nakahara Y, Hosomi Y, Saito M, Ogawa M, Hishima T, Okamura T, Sasaki J and Masuda N: Predictive significance of thyroid transcription factor-1 expression in patients with non-squamous non-small cell lung cancer with wild-type epidermal growth factor receptor treated with erlotinib. Mol Clin Oncol 5: 14-18, 2016.

9. Hosny Mohammed K, Ewaz A, Cohen C and Siddiqui MT: Double staining: Diagnostic utility in non-small cell lung carcinoma in the era of tissue conservation. J Am Soc Cytopathol 6: 170-175, 2017.

10. Sun JM, Han J, Ahn JS, Park K and Ahn MJ: Significance of thymidylate synthase and thyroid transcription factor 1 expression in patients with nonsquamous non-small cell lung cancer treated with pemetrexed-based chemotherapy. J Thorac Oncol 6: 1392-1399, 2011.

11. Puglisi F, Barbone F, Damante G, Bruckbauer M, Di Lauro V, Beltrami CA and Di Loreto C: Prognostic value of thyroid transcription factor-1 in primary, resected, non-small cell lung carcinoma. Mod Pathol 12: 318-324, 1999.

12. Elsamany SA, Al-Fayea TM, Alzahrani AS, Abozeed WN Darwish W, Farooq MU, Almadani AS and Bukhari EA: Thyroid transcription factor-1 expression in advanced non- small cell lung cancer: Impact on survival outcome. Asian Pac J Cancer Prev 16: 2987-2991, 2015. 
13. Berghmans T, Paesmans M, Mascaux C, Martin B, Meert AP, Haller A, Lafitte JJ and Sculier JP: Thyroid transcription factor 1 - a new prognostic factor in lung cancer: A meta-analysis. Ann Oncol 17: 1673-1676, 2006.

14. Kim JH, Kim HS, Kim BJ, Han B, Choi DR and Kwon JH: Prognostic impact of TTF-1 expression in non-squamous non-small-cell lung cancer: A meta-analysis. J Cancer 9: 4279-4286, 2018.

15. Yang A, Kaghad M, Wang Y, Gillett E, Fleming MD, Dötsch V, Andrews NC, Caput D and McKeon F: p63, a p53 homolog at 3q27-29, encodes multiple products with transactivating, death-inducing, and dominant-negative activities. Mol Cell 2: 305-316, 1998

16. Ma Y, Fan M, Dai L, Kang X, Liu Y, Sun Y, Xiong H, Liang Z, Yan W and Chen K: Expression of p63 and CK5/6 in early-stage lung squamous cell carcinoma is not only an early diagnostic indicator but also correlates with a good prognosis. Thorac Cancer 6: 288-295, 2015.

17. Pelosi G,Pasini F, Olsen Stenholm C, Pastorino U, Maisonneuve P, Sonzogni A, Maffini F, Pruneri G, Fraggetta F, Cavallon A, et al: p63 immunoreactivity in lung cancer: Yet another player in the development of squamous cell carcinomas? J Pathol 198: 100-109, 2002

18. Matej R, Dundr P, Hornychova H, Ryska A and Ticha I: Nádory plic - doporučený postup pro bioptické vyšetření. Společnost českých patologů, 2019. http://www.patologie.info/soubory/ all/2019-5_Guideline-pl\%C3\%ADce-web.pdf.

19. Eisenhauer EA, Therasse P, Bogaerts J, Schwartz LH, Sargent D, Ford R, Dancey J, Arbuck S, Gwyther S, Mooney M, et al: New response evaluation criteria in solid tumours: Revised RECIST guideline (version 1.1). Eur J Cancer 45: 228-247, 2009.

20. Reck M, van Zandwijk N, Gridelli C, Baliko Z, Rischin D, Allan S, Krzakowski M and Heigener D: Erlotinib in advanced non-small cell lung cancer: Efficacy and safety findings of the global phase IV Tarceva Lung Cancer Survival Treatment study. J Thorac Oncol 5: 1616-1622, 2010.

21. Germonpré P and Van den Wyngaert T: Second-line erlotinib after failure of pemetrexed-containing chemotherapy in advanced non-small cell lung cancer (NSCLC): Real-world effectiveness, safety and tolerability. PLoS One 14: e0215135, 2019.

22. Hirai F, Edagawa M, Shimamatsu S, Toyozawa R, Toyokawa G, Nosaki K, Yamaguchi M, Seto T, Takenoyama M and Ichinose Y: Evaluation of erlotinib for the treatment of patients with non-small cell lung cancer with epidermal growth factor receptor wild type. Oncol Lett 14: 306-312, 2017.

23. Zhang YL, Yuan JQ, Wang KF, Fu XH, Han XR, Threapleton D, Yang ZY, Mao C and Tang JL: The prevalence of EGFR mutation in patients with non-small cell lung cancer: A systematic review and meta-analysis. Oncotarget 7: 78985-78993, 2016.

24. Faehling M, Eckert R, Kuom S, Kamp T, Stoiber KM and Schumann C: Benefit of erlotinib in patients with non-small-cell lung cancer is related to smoking status, gender, skin rash and radiological response but not to histology and treatment line. Oncology 78: 249-258, 2010.
25. Yang L, Lin M, Ruan WJ, Dong LL, Chen EG, Wu XH and Ying KJ: Nkx2-1: A novel tumor biomarker of lung cancer. J Zhejiang Univ Sci B 13: 855-866, 2012.

26. Kerr KM: Personalized medicine for lung cancer: New challenges for pathology. Histopathology 60: 531-546, 2012.

27. Haque AK, Syed S, Lele SM, Freeman DH and Adegboyega PA: Immunohistochemical study of thyroid transcription factor-1 and HER2/neu in non-small cell lung cancer: Strong thyroid transcription factor-1 expression predicts better survival. Appl Immunohistochem Mol Morphol 10: 103-109, 2002.

28. Zhu WY, Hu XF, Fang KX, Kong QQ, Cui R, Li HF, He JY, Zhang YK and Le HB: Prognostic value of mutant p53, Ki-67, and TTF-1 and their correlation with EGFR mutation in patients with non-small cell lung cancer. Histol Histopathol 34: 1269-1278, 2019

29. Fiala O, Pesek M, Skrickova J, Kolek V, Salajka F, Tomiskova M, Satankova M, Kultan J, Kuliskova J, Svaton M, et al: Thyroid transcription factor 1 expression is associated with outcome of patients with non-squamous non-small cell lung cancer treated with pemetrexed-based chemotherapy. Tumour Biol 39: 1010428317691186, 2017

30. Chatziandreou I, Tsioli P, Sakellariou S, Mourkioti I, Giannopoulou I, Levidou G, Korkolopoulou P, Patsouris E and Saetta AA: Comprehensive Molecular Analysis of NSCLC; Clinicopathological Associations. PLoS One 10: e0133859, 2015.

31. Zamboni $\mathrm{M}$ and Civitareale D: TTF-1/Nkx2.1 functional connection with mutated EGFR relies on LRIG1 and $\beta$-catenin pathways in lung cancer cells. Biochem Biophys Res Commun 505: 1027-1031, 2018

32. Phelps CA, Lai SC and Mu D: Roles of Thyroid Transcription Factor 1 in Lung Cancer Biology. Vitam Horm 106: 517-544, 2018.

33. 34. Yoh K and Prywes R: Pathway Regulation of p63, a Director of Epithelial Cell Fate. Front Endocrinol (Lausanne) 6: 51, 2015.

34. Holcakova J, Nekulova M, Orzol P, Nenutil R, Podhorec J, Svoboda M, Dvorakova P, Pjechova M, Hernychova L, Vojtesek $\mathrm{B}$, et al: $\triangle \mathrm{Np} 63$ activates EGFR signaling to induce loss of adhesion in triple-negative basal-like breast cancer cells. Breast Cancer Res Treat 163: 475-484, 2017.

35. Patel TS, Shah MG, Gandhi JS and Patel P: Accuracy of cytology in sub typing non small cell lung carcinomas. Diagn Cytopathol 45: 598-603, 2017.

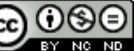

This work is licensed under a Creative Commons Attribution-NonCommercial-NoDerivatives 4.0 International (CC BY-NC-ND 4.0) License. 